(see go.nature.com/u4mgyq and go.nature.com/8ig9oy).

The neuroscience currently funded by the BBSRC must survive a rigorous committee selection process. According to the research council, the cut is being imposed not because the neuroscience funded is less than excellent, but because it does not address BBSRC priority areas.

Yet neuroscience research is crucial in every BBSRC priority area. In public health, it can improve the understanding of mental illness, age-related cognitive decline, and diet and exercise factors (through the neural basis of food selection and motivation, respectively). It can improve animal welfare by giving insight into the mental state of farm animals, and is relevant to food security - for example, by controlling crop predation through knowledge of the neural basis of insect behaviour.

The BBSRC funds so much of this research because of the high quality of British neuroscience and because its researchers have consistently proved that they can compete for funding.

So far, the BBSRC has been admirably responsive to research excellence on the ground, and open to going where scientists lead. This imposition of funding priorities from the top is a regrettable change.

Peter A. McNaughton, Trevor W. Robbins University of Cambridge, UK. pam42@cam.ac.uk

\section{Easier citizen science is better}

Non-scientists are now participating in research in ways that were previously impossible, thanks to more web-based projects to collect and analyse data. Here we suggest a way to encourage broader participation while increasing the quality of data.

Participation may be passive, as when someone donates their computer's 'downtime' to projects such as SETI@home, or active, as when someone uses eBird to log birds they have spotted. Unfortunately, the prevailing data-collection and storage practices for active projects inhibit participation by non-experts.

Many projects rely on positive identification, whether explicitly (as for eBird) or by soliciting photographs and descriptions that others can use to classify the observation (as for the UK website iSpot). Because nonexperts often lack the knowledge to identify species, they may opt not to participate or may provide inaccurate data by accidentally misidentifying something. The result is a trade-off between participation and data quality.

This trade-off can be avoided simply by changing the way information is collected and stored. Participants should be given the option to report a sighting in terms of observed attributes, eliminating the need to force a (possibly incorrect) classification. For example, allowing someone to report a bird as oil-covered may be more valuable than asking them to guess what the species is. For such data to be used effectively, they need to be stored in a way that supports attributes rather than fixed, predetermined classes.

Jeffrey Parsons, Roman Lukyanenko and Yolanda Wiersma Memorial University of Newfoundland, Canada.

jeffreyp@mun.ca

\section{Include Israel when comparing metrics}

Your readers deserve to see research metrics from the Arab world (Nature 469, 453 and 470, 147; 2011) compared with those of its nearest neighbour, Israel.

You compare the number of publications, researchers per million of population and the percentage of gross domestic product (GDP) expended on research and development (R\&D). But all of your graphics omit Israel, even though the GDP graphic includes the European Union and Turkey.

The picture would be different had Israel's metrics been included. Israel published 14,943 papers in 2008 (Science
Citation Index). In 2007, there were 7,841 researchers per million population, and civilian expenditure on R\&D totalled $4.3 \%$ of GDP in 2009 - the highest percentage in the world (Central Bureau of Statistics, State of Israel).

From 1948, Israel and its Arab neighbours started on a roughly equal footing. Israel has achieved much, despite arguably being the poorer nation in terms of traditional measures such as land area, natural resources and freedom from conflict. Its strong investment in human capital, fostered by a free and open society, has produced six decades of spectacular growth. Those achievements stand in contrast to six decades of regrettably slow (and relatively static) progress in the Arab world. Your analysis would have been more accurately portrayed in this context.

David W. Borhani Hartsdale, New York, USA.

david.borhani@alum.mit.edu

\section{Lay aside the ladder of descent}

Your argument that the curious Xenoturbella flatworm represents a "crucial intermediate stage of animal evolution" (Nature 470, 161-162; 2011) perpetuates a popular misconception, stemming from a presumption that the features of such ancient living relics are intermediate between those of other extant creatures.

Today's organisms are all at the twig tips of one large tree of life, with no knowable connections between primitive and higher forms. Reproductively isolated populations of species, such as chimpanzees and humans, are not modifications on a 'ladder' of descent - thus living chimpanzees are not our ancestors, but a sister species adapted to a different habitat (tropical forests versus savannah).

Xenoturbella has largely maintained its internal structure and body shape over millions of years of evolution, during which stabilizing selection removed descendants that were less-well adapted to their environment than their parents.

Such 'living fossils' have always occupied a narrow ecological niche, apparently without ever experiencing much competition from more complex organisms, and so may serve as models for reconstructing crucial steps in animal evolution. But they do not represent 'intermediate' evolutionary forms in the way that some of the famous fossils from the Mesozoic, such as the feathered dinosaurs or ancient snakes with hind legs, are viewed as earlier, extinct connecting links in the tree of life.

U. Kutschera Institute of Biology, University of Kassel, Germany. kut@uni-kassel.de

\section{India needs more plant taxonomists}

India, with its wide range of geographical and climatic conditions, has a rich and varied flora of some 45,000 species - almost $7 \%$ of the world's flowering plants. But their documentation is seriously compromised by the country's dearth of plant taxonomists.

Although DNA sequence data and barcoding are well on the way to being accepted as the global standard for species identification, India's plant taxonomists are struggling to keep up. A lack of proper training and infrastructure hampers molecular-systematics studies, so the evolutionary lineages of most of the country's plants remain poorly understood.

India's many outstanding botanists, familiar with regional flora, must help plant taxonomists to advance molecular-systematics studies and improve the evolutionary understanding of the country's rich biodiversity.

M. Ajmal Ali King Saud University, Saudi Arabia. majmalali@rediffmail.com R. K. Choudhary Korea Research Institute of Bioscience and Biotechnology, South Korea. 